\title{
Justis P. Ehlers (ed): The retina illustrated
}

\section{9, 448 pp, 407 illustrations Paperback/softback, ISBN: 9781626238312 Thieme Publishers New York/Stuttgart}

\author{
Ajay Kotagiri ${ }^{1}$ - David H. Steel ${ }^{1}$
}

Received: 27 June 2020 / Revised: 27 June 2020 / Accepted: 6 July 2020 / Published online: 14 July 2020

(C) Springer-Verlag GmbH Germany, part of Springer Nature 2020

The editor of this well-illustrated book states in the preface that they aim to provide a quick reference guide on retinal disorders to eye care providers. They made a valiant attempt to achieve this mammoth task, and have included multiple types of retinal pathology from medical, surgical, uveitic and oncology sub-specialities into a small and concise textbook with excellent images.

Retinal practice has become increasingly dependent on imaging. Indeed, there has been significant progress in imaging modalities in recent years ranging from wide-field imaging to optical coherence tomography angiography (OCT-A). The book begins with the theory and interpretation of these modern imaging techniques and progresses smoothly through different types of retinal pathologies in the next 9 sections. The discussion is very well balanced. As an example, OCT-A artifacts are described in very simple but clear terminology.

A number of authors and specialists from different parts of the world have contributed to the various chapters, so that all the major conditions globally are covered in sufficient detail. There is good coverage of common pathologies as well as uncommon conditions, which may only be seen rarely by general ophthalmologists.

Each chapter starts with a summary of the investigation or the pathology concerned then continues to the clinical features and management, covering the subjects clearly and concisely. This is accompanied by excellent example illustrations ranging from colour photographs to angiography images. This style of presentation gives a quick and practical guide when

Ajay Kotagiri

ajay.kotagiri@chsft.nhs.uk

David H. Steel

david.steel@ncl.ac.uk

1 Department of Ophthalmology, South Tyneside and Sunderland NHS Trust, Sunderland Eye Infirmary, Queen Alexandra Road, Sunderland SR2 9HP, UK needed. Theory is not totally forgotten by including tables, classifications and staging including those for example of sickle cell retinopathy and Bests disease. Usefully, there is a balanced list of references in terms of further suggested reading at the end of each chapter. This offers the reader a chance to enhance their knowledge on the topic and guides them readily to the best sources.

Another strength of the book lies in the fact that it covers common topics of age-related macular degeneration whilst also including extremely rare ones like Zika virus retinopathy. The illustrations are of excellent quality with clear annotations to identify the pathology. Even though not described separately in the investigations chapter, older modalities of investigation like B-scan ultrasound are not forgotten, but used in conjunction with the newer techniques for example in chapters of choroidal folds, retinal detachment and trauma. The book also includes recently recognized conditions including retinopathy secondary to targeted cancer therapies, which are becoming more common and not covered in existing textbooks. A further developments' section in some of the chapters covers the possible direction of future research.

Inclusion of more niche topics, which are normally omitted in retinal imaging books such as intraoperative OCT, imaging features of both blunt and penetrating trauma and retinopathy of prematurity, makes this book useful for a range of retinal specialists including surgeons, trauma specialists and paediatric ophthalmologists. The authors have wisely avoided multiple in text referencing to keep the book simple and easy to read.

Over all, this is a very valuable addition to retina atlas style books with its own unique advantage of being small but thorough, covering an extensive range of topics including recent advances, helping readers interpret and manage retinal conditions more effectively for our patients' benefit.

Publisher's note Springer Nature remains neutral with regard to jurisdictional claims in published maps and institutional affiliations. 